\title{
Resilience and economic intelligence build through digitalization - an IT perspective
}

Iulia Daniela Postolea, Economic Informatics Doctoral School, iulia.d.postolea@gmail.com

Constanta-Nicoleta Bodea, Department of Informatics and Economic Cybernetics, bodea@ase.ro

\begin{abstract}
In the present times defined by fierce full events, low predictability and complexity, resilience represents an attribute which should be present in all parts of the company, at an individual, department or project level. The authors have identified digital transformation as being a main pillar in building resilience and have conducted a research in order to explore the two concepts as well as the connection between them. The present paper may be considered an extension of a previous research which was focused rather on interviewed profiles coming from business environment with a component of financial responsibility, the present study being focused on profiles coming from IT domain with management responsibility. The main findings of the research refer to the perception of resilience, digital transformation and the connection with the corporate finance field as observed by the IT profile respondents and the comparison with the findings resulted from the previous study.
\end{abstract}

Keywords: Resilience, artificial intelligence, digital transformation, financial resilience

\section{Introduction}

Resilience, a concept rather new for some fields, has become one of the key components of the company's strategy, placed as a concept, as an attribute or part of a continuous effort which an entity might pursue at some point in time. When trying to define resilience, adaptative capacity and its ability to cope with, adapt to and recover after a disruption (Gallopin, 2006) is the straightforward description of the concept.

The concept of resilience includes technological, institutional, and behavioral components, and implies an active response to mitigate the consequences of the shock. Masten et al. (1990) defined resilience as the process of, capacity for, or outcome of successful adaptation despite challenging or threatening circumstances, while Bonnano (2005) identifies that adult adversities are more likely to be isolated.

From a financial perspective, Jacobsen places resilience in connection with vulnerability defining them as being "two sides of the same coin", leading to an assessment of the resources from the perspective of sufficiency, quality, access to them. On the other hand, McKinsey consultancy firm (Laczkowski et al.2019) discusses on how to take advantage through the perspective of resilience on disruptions and the opportunities brought with them - fast adaptation in reducing operating costs, building on the recovery momentum and taking advantage of the increasing revenues, once the recovery period has started would be a couple of the key elements which companies should seek after. 


\section{Issues in Information Systems}

Volume 22, Issue 1, pp. 335-347, 2021

Digital transformation, considered as being the process of using digital technologies to create and/or modify business processes, culture, client experiences, generating information based on existing data and fast decision taking in terms of time and cost, is an important pillar on which organizations can ground its internal structure, strongly contributing to flexibility and agility - concepts linked with resilience and the ability to respond and adapt faster due to accessibility of the information, leading thereby to informed and quick decisions.

The paper intends to bring into discussion concepts like resilience, at company level and from corporate finance perspective, digital transformation and the linkage between them through the perception of handon professionals from IT field, with the purpose to identify triggering factors as well as backtrack elements and a comparison of the results with a previously conducted research which was focusing on the business perception of the discussed concepts.

\section{Background and literature review}

In the reviewed literature, resilience has been debated by several authors in connection with different concepts or from several perspectives - definition and metrics to quantify its level, stages of disruption, attributes that define resilience or in the organizational approach, result oriented processes or emergent feature of a system.

Dalziell and McManus (2004) represent companies as being highly complex and dynamic entities, therefore an approach like simply identifying cause and effect relationships is considered trivial, underlying the difficulty to understand the impact of a particular decision or action on the overall system. The authors focus their research around vulnerability, adaptive capacity and resilience as connected concepts; resilience is described under two perspectives - engineering resilience - defined as the speed to return to steady state following the perturbation, which implies a focus on efficiency of function and ecological resilience - being the magnitude of disturbance that can be absorbed before the system restructures, which implies a focus on maintaining existence of function (Gunderson and Pritchard, 2002) and which of the attributes would fit the best to the organizational resilience.

Dalziell and McManus (2004) bring an interesting perspective on two aspects - what should recovery mean and how can resilience be measured. Recovery is brought in discussion on a different perspective if compared with Erol in the sense that an organization should not aim to recover and build itself to be the same as it was before the disaster struck, but should reshape to a new equilibrium, where it can regain synergy with its external environment. When discussing about the resilience measurement, "that which isn't measured, isn't managed" - any real progress in getting organizations to invest to become more resilient has to be measured and benchmarked and moreover the challenge to ensure that the metrics are meaningful to those who influence the organization are framed and debated under different perspectives.

The basis for the resilience measurement proposed by the two authors refer to: - articulation of the system purpose and defining a system boundary; - identification of the different components that the system requires in order to achieve the system purpose; - examination of the relationship between these different components and understand how they interact in order to achieve the system purpose; - review on how system interact with the environment, its influence on environment and the changes determined within the system by the environment. 


\section{Issues in Information Systems}

Volume 22, Issue 1, pp. 335-347, 2021

From the perspective of resilience as emergent feature of a system, Haimes et al. (2008) define a set of attributes of the systems that are not identified in advance but are emerging based on events that create the motivation and the responses for properties that ultimately end up into system features. Resilience is seen from this perspective as a feature of dynamic systems and as a result from the interaction of the characteristics and capacities of an enterprise which is evolving when facing a disruptive event, as well as a resulting ability to adapt and recover from it. Further on, Haimes also considers resilience as emerging feature for system of systems indicating that system of systems performs functions and carries out meanings that do not reside in any component system, and that these behaviors are emergent properties of the entire system of systems and not the behavior of any component system. In this perspective, component systems are typically designed independently (not as a part of a larger system), controlled autonomously, and then integrated in a distributed and loosely coordinated process.

Wreathall (2006) presents resilience as the result of necessary processes, considering that resilience is not a one-time event, but rather a spread over time from pre-event strategies to post-recovery actions. The processes included in the paper in relation with resilience include functions and tasks to prevent, protect, respond and recover. According to the author, "what" has to be done and "how" it can be accomplished are to be identified and performance measures should be attained. The conclusion of the paper is the enterprise resilience is the outcome of a continuous process, including planning for resilience, responding to threats in case of disruptions and taking adaptive measures in order to recover.

When switching the focus to information systems like big data analytic, it has been identified that it may be fundamental in further to conceptualize a framework around resilience in connection with artificial intelligence, big data, flexibility, agility considering the importance of such transformations in achieving organizational resilience. Ciampi et al. (2018) present a system through which Big Data Analytics (BDA) is a pillar on which resilience can be build based on the following hypothesis: - Integrating artificial intelligence capabilities into management information systems is fundamental in transforming traditional management information systems into BDA capable information systems; - BDA capable information systems may influence the organizational pursuit of flexibility and agility; - Strategic flexibility and agility deriving from BDA capable information systems may foster organizational resilience; - BDA capable information systems, due to their artificial intelligence capabilities, may increase organizational resilience.

Zohuri and Rahmari (2019) bring an interesting perspective on artificial intelligence driven resiliency with machine learning and deep learning components, drawing attention to the importance of processing big amount of data - Big Data and how the next generation of robots move things into the Super Artificial Intelligence (SAI) era. In this paper, the authors present how Big Data demonstrates its benefits in different industries - government - by applying analytics to the high amount of information available and gain significant ground when it comes to managing utilities, dealing with traffic congestions, or preventing crime; - education - making sure that the students are making the adequate progress and to implement a better system for evaluation and support for teachers and principals; - banking - understanding the customers and increasing their satisfaction as well as minimizing the fraud risk by maintaining regulatory compliance requirements; - healthcare - ensuring quick and accurate handling of the data for patient records, treatment plans, prescription information in order to uncover hidden insights the improve the patient care; - manufacturing - reducing waste as well as taking rapid, informed decisions about the maintenance and production portfolio; - retail - customer relationship management and customer behavior through buying choices and - stock market - deep learning techniques used for predicting the movement on the market.

Davenport and Redman (2020) identify 4 key areas when addressing digital transformation on a strategic level: - technology: technical debt of existing systems and legacy technologies are difficult to 


\section{Issues in Information Systems}

Volume 22, Issue 1, pp. 335-347, 2021

change and only by handling the ability to work hand in hand with the business, these challenges will be surpassed; - data: its quality, breadth and depth is crucial for creating valuable conclusions and effective decisions; - process: handling knowledge silos within an organization, an end-to-end mindset, rethinking ways to meet customer needs are the focus areas when radical process engineering is considered, together with the integration of an adapted agile IT governance framework; - organization change capacity: leadership, teamwork, courage, emotional intelligence are the main elements of change management in the context of digital transformation.

Relating to the recent crisis caused by the COVID-19 pandemic, Papagiannidis, Harris and Morton (2020) present how digital transformations took place from an IT perspective the period before the pandemic, the response to the pandemic and the period after it, identifying key lessons to be learned and challenges faced during this period.

When focusing on the period after the pandemic will pass in the context of building resilience from a digital transformation perspective, IT is seen as a service that serves the business continuity, the actual impact coming from critical employee groups, business processes, infrastructure and data, external relationships, viewpoint from which organizations need to prioritize decisions and investments based on roles and tasks instead of hierarchy. Building resilience in this way is likely to be cost effective, as disruptive incidents of a smaller scale are likely to occur intermittently and the organization will need to respond and adapt over time, creating an automatic failover culture.

In a world where technological and industrial revolution has been accelerated by the widespread application of new generation information, artificial intelligence has attracted a lot of attention from governments, industry, and academia (Zhang and Lu, 2021). The first-time scholars have mentioned the term of Artificial Intelligence (AI) was in 1956 at a conference in Dartmouth University, being the starting point of studying how machines simulate human intelligent activities. AI as it is known today is a compilation of computer science, logic, biology, psychology, philosophy, and many other disciplines with reaching great accomplishments in the filed of speech recognition, image processing, natural language processing, the improving of automatic theorems, and intelligent robots (Duan et al., 2014)

The last years have seen an exponential increase in the volume, variety, velocity, and the value of large amounts of data, being the emergent factors of Big Data processing trends, in particular fast analytics and data science becoming part of the business intelligence or Big Data analytics implementation within organizations dealing with universal digital data (Larson and Chang, 2016). Big Data enhances the organizations to identify relevant information that otherwise would not be visible with the consideration of the emerging Big Data tools - text mining, web mining, social network analysis, mobile and multimedia mining - through which the companies, based on the diverse competitor data sets, can gain insight of the impact or the potential inconsistencies.

Hu (2021) discusses in his paper three-way data analytics based on two stages of data analytics (data preparation and data analysis) and the Data-Information-Knowledge-Wisdom hierarchy by organizing the existing three-way topics into three bunches - three-way data preparation concerning data, three-way data analysis concerning information, and three-way data analysis concerning knowledge and wisdom.

Many popular topics of applying thinking in threes under the framework of three-way decision are related 


\section{Issues in Information Systems}

Volume 22, Issue 1, pp. 335-347, 2021

to the process of data analytics. Based on this observation, the paper published by HU presents the term of three-way data analytics, which enables to explore existing and potential topics of thinking, computing, and processing with threes from a broad view of data analytics.

A connected concept related to Big Data proposed by Ranjan and Foropon (2021) is competitive intelligence which is defined as the collection, analysis, interpretation, and dissemination of strategic information at the right time to make use in the decision-making process. A small organization with a progressive attitude towards Big Data may be able to carve out a competitive advantage against a much bigger rival firm only by understanding their niche in the data market better. As long as companies have hard-rock data - from both internal and external resources - the ingenious analysis of such data will produce competitive advantage.

The authors propose a novel framework to illustrate how organizations can leverage Big Data analytics to enhance business value, understanding competitors moves by collecting both structured and unstructured data - for example advanced Big Data methods can send alerts to the decision makers within the company regarding real-time market fluctuations, customer mobility, may enable the understanding of the triggers in competitor's strategies, contribute when readjustment of internal promotions or policies are needed.

As a conclusion, the study aims to understand competitive intelligence in the analyzed business areas (IT, consumer goods, Fintech) and the appropriate Big Data approach for it, raising awareness that only two choices are available in the present times: continue to be skeptical on Big Data assets or embrace Big Data nuggets to discover new managerial insights.

A different perspective on Big Data is brought by Routledge (2021) is that Big Data causes big firms thereby creating a connection to the size of the company. Technology represented by the devices that generate and collect data has contributed to the expending phenomenon called Big Data; by adding the evolution of the computer technology, in the present we can make accessible the result of the processing of large data in parallel and in addition machine learning statistical models like deep learning and neural networks can be effective at drawing inferences from large data sets. Moreover, advances in optimization algorithms have made estimating these statistical models on large data sets using distributed computing feasible.

In contrast, a complete look at how Big Data and technology have changed company size dynamics could also include a look at the impact of data and technology on new-firm creation. Much of the Big Data software for machine leaning is open source, therefore many of the Big Data models run on cloud-based servers that use rented capital.

The focus of this approach is mainly in reviewing the existing research in this field by formulating findings that emerged in the existing literature, thereby having a gap in addressing the practical/business part, further investigation with qualitative methodologies being one of the necessities. 


\section{Methodology}

Bearing in mind the limitation brought by theoretical background of the concepts, the considered research method was inductive inquiry. Data was collected in semi-structured interviews. The interviewees' profile are presented in table 1.

Table 1: Interviewees' profile

\begin{tabular}{|l|l|l|l|}
\hline Interviewee & \multicolumn{1}{|c|}{ Domain } & $\begin{array}{c}\text { Experience } \\
\text { (no. of years) }\end{array}$ & $\begin{array}{c}\text { Company size } \\
\text { (turnover, in mil. } \\
\text { Euros) }\end{array}$ \\
\hline LV & Technology and telecommunication & $>5$ & $>100$ \\
\hline CP & Business and Financial services & $>10$ & $<50$ \\
\hline BM & Automotive & $>5$ & $>100$ \\
\hline AM & Technology and telecommunication & $>10$ & $>100$ \\
\hline LG & Government and public services & $>15$ & $<10$ \\
\hline AA & Business and Financial services & $>5$ & $<50$ \\
\hline
\end{tabular}

The present paper may be considered an extension of a study which is under publication referring to the same concepts when addressing the perception of resilience and digital transformation with responding profiles activating in the area of business and/or financial responsibility.

The following interview sections were defined:

1. Resilience and digital transformation perception (How the resilience is perceived? Is resilience important? Which are the difficulties during building the resilience?)

2. Digital transformation strategy, as defined or being defined (Did the company already defined or is interested to define a strategy for digital transformation? Which are determining factors that would lead to a digital transformation strategy? What kind of technologies can be considered as part of the digital transformation? Which are the relevant changes when implementing different tools/technologies/applications? How the actual mindset/culture of the company fits to the digital transformation trends and digital transformation strategy, if exists? Are there any initiatives designed for a cultural transformation also and if yes, could you please provide an example?)

3. Digital transformation and financial resilience (How financial resilience contributes to an overall company resilience? How the digital transformation process leads to building resilience in the finance field? Are there any particularities of digital transformation in the finance field? Which are the emerging digital trends in the finance field?)

4. Build resilience through digital transformation (Would the resilience lead to a sustainable growth of the company? How can it reshape the future of the company for the next 5 - 10 years?)

In order to prepare the interviews, a prior verbal consent of participation was obtained with the agreement of not disclosing the name of the companies for which the participants of the study are working. The interview protocol was sent via email prior to the meeting with a transcript from the of the conversation. The transcripts of the interviews were analyzed using coding techniques based on which groups of codes 


\section{Issues in Information Systems}

Volume 22, Issue 1, pp. 335-347, 2021

and identified linked concepts have been defined. The results presented in the following section bring a comparative perspective on how business and financial people responded at the same questions in comparison with profiles from the IT domain.

\section{Results/findings}

The first section of the research focuses on resilience at a company level - concept, attributes, impact, financial resilience as connected concept (see table 2). In order to ensure a proper comparison level, the input received from the two groups - business environment and IT domain - is done based on the primary codes, keeping the code groups the same.

Table 2: Company resilience

\begin{tabular}{|c|c|c|}
\hline Preliminary Codes & Code groups & Categories \\
\hline $\begin{array}{l}\text { - } \quad \text { Changes implementation } \\
\text { - } \quad \text { Company survival or thriving } \\
\text { - } \quad \text { Processes improvement and optimization }\end{array}$ & Dealing with changes & \multirow[t]{3}{*}{$\begin{array}{l}\text { Company } \\
\text { resilience (CR) } \\
\text { concept }\end{array}$} \\
\hline $\begin{array}{l}\text { - People-related challenges (risk taking profile, decision } \\
\text { making abilities, driving changes, stress level burnout) } \\
\text { - Business interdependencies } \\
\text { - Market negative trends }\end{array}$ & Challenges & \\
\hline $\begin{array}{l}\text { - } \quad \text { Company proactive/reactive behavior } \\
\text { - } \quad \text { People and. company resilience }\end{array}$ & Types and levels & \\
\hline $\begin{array}{ll}\text { - } & \text { Resilience and risk management } \\
\text { - } & \text { Resilience and profitability tradeoff } \\
\text { - } & \text { Business evolution/predictions }\end{array}$ & General approach & \multirow[t]{2}{*}{ CR attributes } \\
\hline $\begin{array}{ll}\text { - } & \text { Commitment to mission and vision } \\
\text { - } & \text { Managerial quality } \\
\text { - } & \text { Financial stability }\end{array}$ & Premises & \\
\hline $\begin{array}{ll}\text { - } & \text { Company maturity } \\
\text { - } & \text { Company life cycle Stage }\end{array}$ & Factors & \multirow[t]{2}{*}{ CR impact } \\
\hline $\begin{array}{ll}\text { - } & \text { Company robustness } \\
\text { - } & \text { Company survival } \\
\text { - } & \text { Company prosperity } \\
\text { - } & \text { Business improvement } \\
\text { - } & \text { New markets } \\
\text { - } & \text { Go to market KPIs, } \\
\text { - } & \text { Market share increasing }\end{array}$ & Effects & \\
\hline $\begin{array}{ll}\text { - } & \text { FR necessity } \\
\text { - } & \text { Financial policies, as FR basis } \\
\text { - } & \text { Liquidity and assets, as FR factors } \\
\text { - } & \text { Resources as services } \\
\text { - } & \text { Smart people with smart technologies }\end{array}$ & Characteristics & $\begin{array}{l}\text { Financial } \\
\text { resilience (FR) } \\
\text { concept }\end{array}$ \\
\hline
\end{tabular}




\section{Issues in Information Systems}

Volume 22, Issue 1, pp. 335-347, 2021

\begin{tabular}{|ll|l|l|}
\hline$-\quad$ FR, as CR trigger & Impact on CR & \\
- & FR for strategy modeling & & \\
- & Opts behind costs, as decision criteria & & \\
\hline
\end{tabular}

From the conceptual perspective of resilience, both groups have a common understanding in addressing changes and challenges focusing on continuing and improving processes, implementing changes with a focus on positive and efficient reaction to it, considering risk management, but also related impact on an employee level. The types and levels of resilience are seen from different perspectives - the business part focusing more on the levels within the company and its sustainability over time, when IT perspective focuses more on company as general entity vs. people and on proactivity/reactivity coming from those. The attributes section reveals - both from general approach perspective as well as the premises considered for it - a different perception: the business environment focuses more on a holistic approach with strategical components, focusing on operational details considering resources versus the IT domain which tends to be more specific - differencing resilience and risk management, tradeoff between achieving resilience and the profitability indicators.

The effects of the resilience at the company level are perceived in the same way by both groups considered factors being the company - from its maturity, life-cycle stage, inertia, as well as effects coming out when achieving resilience - increase market share, business improvement, cultural transformation etc.

Financial resilience - stand alone or as a contributor to the company, both as a characteristic or as the impact on the organizational level - is seen as a key contributor with an important prediction component and a pillar in improving the financial position of the company - either by reduction of the operational cost or orientation of processes and data driven activities with less dependency on people.

Table 3: Digital transformation for building the company resilience

\begin{tabular}{|l|l|l|}
\hline Preliminary Codes & Code groups & Categories \\
\hline$-\quad$ Digital setup/preparation & General & DT for CR \\
- DT and organizational culture & approach & \\
- DTanging the managerial style & & \\
- Management Level C commitment and alignment & & \\
$-\quad$ Highly customized vs. highly standardized processes/IT solutions & & \\
$-\quad$ Physical processes digitalization & & \\
$-\quad$ Organizational changes for DT & & \\
\hline
\end{tabular}




\section{Issues in Information Systems}

Volume 22, Issue 1, pp. 335-347, 2021

\begin{tabular}{|c|c|c|}
\hline $\begin{array}{ll}\text { - } & \text { DT potential } \\
\text { - } & \text { Capability to consume technologies } \\
\text { - } & \text { Accelerated DT strategy } \\
\text { - } & \text { DT people focus } \\
\text { - } & \text { Professional development for DT } \\
\text { - } & \text { Disruptive IT infrastructure } \\
\text { - } & \text { DT business case } \\
\text { - } & \text { Top management support } \\
\text { - } & \text { IT manager, as DT barrier }\end{array}$ & Characteristics & \\
\hline $\begin{array}{ll}\text { - } & \text { Friendly user experience } \\
\text { - } & \text { Knowledge sharing global solutions } \\
\text { - } & \text { Chatbots } \\
\text { - } & \text { Process automation }\end{array}$ & Applications & \multirow[t]{2}{*}{$\begin{array}{l}\text { Technologies and } \\
\text { applications for } \\
\text { CR }\end{array}$} \\
\hline $\begin{array}{l}\text { - Technology diversity for implementing changes } \\
\text { - CAMSS (Cloud, Analytics, Mobile, Social and Security) } \\
\text { - Blockchain, DevSecOps, Machine Learning, Artificial Intelligence, } \\
\text { RPA, IoT } \\
\text { - ABAP, C++, Java }\end{array}$ & Technologies & \\
\hline $\begin{array}{l}\text { - } \quad \text { External and internal process optimization } \\
\text { - } \text { Agile reactions to changes } \\
\text { - Clients' needs understanding } \\
\text { - Knowledge sharing } \\
\text { - } \quad \text { People overloading } \\
\text { - } \quad \text { Divisions/departments interdependencies }\end{array}$ & $\begin{array}{l}\text { Effects of } \\
\text { technologies } \\
\text { adoption }\end{array}$ & \multirow[t]{2}{*}{ DT impact } \\
\hline $\begin{array}{l}\text { Negative impact in case of: } \\
\text { - } \quad \text { No DT associated risks } \\
\text { - } \quad \text { Support for business scaling } \\
\text { - } \quad \text { Late DT risks } \\
\text { - } \quad \text { Cultural change for DT } \\
\text { - } \quad \text { DT focus on people }\end{array}$ & $\begin{array}{l}\text { Sustainable } \\
\text { growth }\end{array}$ & \\
\hline
\end{tabular}

Table 3 brings into discussion the contribution of digital transformation as a pillar in developing resilience at a company level. From the general approach perspective, perception of the IT domain clearly makes a differentiation - if the business environment has a broad perspective either from general strategy or transforming business models, IT input underlines a lot of specific details - commitment and alignment at a management level, organizational culture, changes in management style (openness and willingness of IT managers to make the step into the change), the challenge in digitalizing physical processes etc.

When moving on to the characteristics side, again IT perspective is more detailed and focused on all aspects that may have to be considered, such as: understanding of digital transformation potential, disruptive IT infrastructure, management support defined as critical factor, IT specialists that may take the role of disturbers in handling digital transformation processes (extended-unintegrated IT teams, ethical issues, reluctant people due to willingness to protect old systems/investments etc.), accelerated digital transformation strategy in comparison with the business environment that considers this section more from the perspective of the interaction external factors like clients, potential risks, regulatory changes. 


\section{Issues in Information Systems}

Volume 22, Issue 1, pp. 335-347, 2021

When approaching technologies and applications for building company's resilience, business side sees the focus through the lens of the user and refers to cloud, collaborative and green technologies while IT approaches these details from the side of the service providers focusing on global solutions for knowledge sharing and assuring easy access with a friendly user experience.

The effects of the technology's adoption are perceived in the same manner by both groups underlying customers needs, optimizing processes - both internally and externally, employee's development, cultural transformation etc.

Resilience as part of a sustainable growth, the last group code part of this section, is seen by the business environment as a skill of the future based on the paradigm shift built on resilient teams as a key success factor. On the other hand, IT input does not agree that digital transformation may lead to sustainable growth but acknowledges that there are negative impacts to be considered if this kind of shift will not be embraced (limited internal growth coming from the lack of support for business scaling with high costs and painful transformation for people and business if digital transformation is implemented with a delay).

Table 4: Digital transformation for financial resilience

\begin{tabular}{|c|c|c|}
\hline Preliminary Codes & Code groups & Categories \\
\hline $\begin{array}{ll}\text { - } & \text { Highly customized software solutions } \\
\text { - } & \text { Customized software integration } \\
\text { - } & \text { Information exchange }\end{array}$ & Actual status & \multirow[t]{3}{*}{ DT for FR } \\
\hline $\begin{array}{ll}\text { - } & \text { Changing financial processes } \\
\text { - } & \text { Financial transactions insights } \\
\text { - } & \text { Planning for contingency } \\
\text { - } & \text { Costs/overhead optimization } \\
\text { - } & \text { Financial processes Digitization } \\
\text { - } & \text { Forecasting and budgeting processes improvement }\end{array}$ & Expected effects & \\
\hline $\begin{array}{l}\text { - Financial departments focus } \\
\text { - } \quad \text { Learning from experiences }\end{array}$ & $\begin{array}{l}\text { DT } \\
\text { particularities } \\
\text { and trends }\end{array}$ & \\
\hline $\begin{array}{l}\text { - } \text { AI, Big data and Blockchain } \\
\text { - } \text { Chatbots } \\
\text { - } \text { e-banking, Instant payments etc } \\
\text { - } \text { Fintech services } \\
\text { - Internet presence technologies } \\
\text { - Business processes automation } \\
\text { - Hardware and software }\end{array}$ & Technologies & \multirow[t]{2}{*}{$\begin{array}{l}\text { Technologies and } \\
\text { applications for } \\
\text { FR }\end{array}$} \\
\hline $\begin{array}{l}\text { - } \quad \text { Financial processes automation } \\
\text { - } \quad \text { Automated control loops } \\
\text { - } \quad \text { Procesiness measurement and reporting } \\
\text { - } \quad \text { Data predictive analysis } \\
\text { - } \quad \text { Financial forecasting }\end{array}$ & Applications & \\
\hline
\end{tabular}

Table 4 includes the perspective of the digital transformation as a contributor to the financial resilience by addressing a few areas - actual status, expected effects, particularities and trends, technologies and applications. When assessing the actual status, digital transformation is present in the finance field with a 


\section{Issues in Information Systems}

Volume 22, Issue 1, pp. 335-347, 2021

focus on automation in accounting, commercial area, reporting etc. but highly customized thereby bringing difficulties in the integration and positioning information exchange as being critical. As for the expected effects, things are seen in a similar way by both groups in the perspective of increasing flexibility (improvement of forecasting and budgeting, changing planning for contingency, better organized, performed and controlled financial processes) as well as optimization of costs.

From the perspective of particularities and trends, technologies and applications, things are seen in a similar way by both interviewed groups - there is a focus on financial department with the power of AI and forecasting tools acknowledged, business process automation and technology megatrends and the applications suited for this area refer to robots, chatbots, prediction tools as well as scenario planning and risk management.

The comparative analysis between the two targeted groups aims to bring different perspectives on the same topics seen through the lens of people involved in different parts of a company - business related with focus on market, clients, internal processes and IT - more detailed oriented and sometimes more reluctant in adopting transformations.

\section{Conclusions}

The present research aims to consolidate the perspective on resilience, digital transformation with the identification of particularities applicable for the finance field. The study is an expansion on a previous one which aimed people from the business field partially having also financial responsibility giving the opportunity to complete the perception on the aforementioned concepts.

The comparison between the two perspectives reveals common areas - addressing changes and challenges focusing on continuing and improving processes, implementing changes with a focus on positive and efficient reaction to it, considering risk management, company attributes - from its maturity, life-cycle stage, inertia, as well as effects coming out when achieving resilience, underlying customer's needs, optimizing processes - both internally and externally, employees development, cultural transformation etc. but also identifies several differences, such as: leaning to be more specific - differencing resilience and risk management, tradeoff between achieving resilience and the profitability indicators, more detailed and focused on aspects like understanding of digital transformation potential, disruptive IT infrastructure, and ending in the most explicit statement that IT specialists may take the role of disturbers in handling digital transformation processes.

Bearing in mind that the future of the companies will include digital transformation and resilience as key attributes, the combined perspectives presented in the paper brings the perception of the two concepts in a different light for both sides - either business side or IT - and intends to raise awareness on different aspects that might not be visible at a glance.

\section{References}

Bonanno, G.A. (2005) Clarifying and extending the construct of adult resilience. Am Psychol; 60: 26567. 
Ciampi, F., Marzi, G., Rialti, R. (2018) Artificial intelligence, Big Data, Strategic Flexibility, Agility, and Organizational Resilience: A conceptual framework based on existing literature. International Conferences WWW/Internet and Applied Computing.

Dalziell, E. P., McManus, S. T. (2004) Resilience, Vulnerability, Adaptive Capacity: Implications for System Performance, in International Forum for Engineering Decision Making (IFED) Stoos, Switzerland.

Davenport, T., Redman, T. (2020) Digital transformation comes down to talent in 4 key areas (accessed 27th of February 2021). Available at: www.hbr.org.

Duan, L., Xu, L., Liu, Y., Lee, J. (2009) Cluster-based Outlier Detection, Ann. Oper. Res. 168 (1) 151168

Gallopin, G. (2006) Linkages between vulnerability, resilience, and adaptive capacity. Global Environmental Change; 16: 293-303.

Gunderson, L.H., Pritchard L. Jr. (Eds) (2002) Resilience and the behavior of Large - Scale Systems SCOPE Series Volume 60. Island Press, Washington DC.

Haimes, Y. Y., Crowther, K., Horowitz, B. M. (2008) Homeland Security Preparedness: Balancing Protection with Resilience in Emergent Systems," Systems Engineering, vol. 11, pp. 287-308.

Hu, M. (2021) Three-Way Data Analytics: Preparing and Analyzing Data in Threes, Information Sciences - Informatics and Computer Science Intelligent Systems Applications

Jacobsen, K., Marshak, A., Griffith, M. (2009) Increasing the Financial Resilience of Disaster-affected populations: Feinstein International Center, p-3.

Laczkowski, K., Mysore, M., Brown, S. (2019) How top companies use resilience strategy to survive and drive through downturns. Retrieved from: https://www.mckinsey.com/business-functions/strategy-andcorporate-finance/our-insights/stronger-for-longer-how-top-performers-thrive-through-downturns.

Masten, A.S., Best, K.M., Garmezy, N. (1990) Resilience and development: Contributions from the study of children who overcome adversity. Dev Psychopathol; 2: 425-44.

Larson, D., \& Chang, V. (2016). A review and future direction of agile, business intelligence, analytics and data science. International Journal of Information Management, 36, 700-710.

Papagiannidis, S., Harris, B., Morton, D. (2020) International Journal of Information Management 55, 102166.

Ranjan, J., Foropon, C. (2021) Big Data Analytics in Building the Competitive Intelligence of Organizations, International Journal of Information Management 56102231.

Routledge, B. (2018) Comments on: Big data in finance and the growth of large firms, by Juliane Begenau \& Maryam Farboodi \& Laura Veldkamp.

Wreathall, J. (2006) Developing Models for Measuring Resilience, John Wreathall \& Co., Inc., Dublin, Ohio. 


\section{Issues in Information Systems}

Volume 22, Issue 1, pp. 335-347, 2021

Zhang, C., Lu, Y. (2021) Study on artificial intelligence: The state of the art and future prospects, Journal of Industrial Information Integration 23100224

Zohuri, B., Rahmani, F.M, (2019) Artificial intelligence driven resiliency with machine learning and deep learning components", Journal of Communication and Computer 15, 1-13. 